\title{
Utility and Limitations of Near-Infrared Spectroscopy during Cardiopulmonary Bypass in a Piglet Model
}

\author{
TAKAHIKO SAKAMOTO, RICHARD A. JONAS, ULRICH A. STOCK, SHIN'ICHI HATSUOKA, \\ MARK COPE, ROGER J. SPRINGETT, AND GEORG NOLLERT
}

Department of Cardiac Surgery, The Children's Hospital and Harvard Medical School, Boston, Massachusetts 02115, U.S.A. [T.S., R.A.J., U.A.S., S.H., G.N.]; and Department of Medical Physics and Bioengineering, University College of London, London, United Kingdom [M.C., R.J.S.]

\section{ABSTRACT}

\begin{abstract}
Near-infrared spectroscopy assessment of cytochrome oxygenation could be a valuable technique to monitor cerebral intraneuronal oxygen delivery during cardiopulmonary bypass. However, the validity of the cytochrome signal has been questioned as it could easily be overwhelmed by the $\mathrm{Hb}$ signal. Fiveto six-week-old control piglets $(n=5)$ underwent cardiopulmonary bypass at $37^{\circ} \mathrm{C}$. Study animals $(n=10)$ received $100 \mathrm{mg} / \mathrm{kg}$ of sodium cyanide to uncouple cytochrome from $\mathrm{Hb}$. Hematocrit was then decreased in steps of 5\% from 35 to $5 \%$ with crystalloid hemodilution. In study piglets, the initiation of cardiopulmonary bypass was associated with oxygenated $\mathrm{Hb}$ increasing from 0 to $62.9 \pm 25.6 \mu \mathrm{M}$ times the differential path-length factor, and oxidized cytochrome a,a3 increasing to $1.9 \pm 1.8 \mu \mathrm{M}$ times the differential path-length factor. Cyanide caused oxygenated $\mathrm{Hb}$ to increase further to $132.3 \pm 48.9 \mu \mathrm{M}$ times the differential path-length factor, and oxidized cytochrome $c$ decreased to -7.0 $\pm 2.6 \mu \mathrm{M}$ times the differential path-length factor as anticipated, confirming uncoupling of electron transport. However, hemodilution subsequently resulted in linear decreases in oxidized cy-
\end{abstract}

tochrome a,a3 $(F=8.57, p<0.001)$ suggesting important cross-talk between the $\mathrm{Hb}$ and cytochrome signals as cytochrome is only intracellular. In control piglets, tissue oxygenation index showed a positive correlation with pump flow $(r=0.986, p=$ $0.013)$. The cytochrome signal as presently measured by nearinfrared spectroscopy is highly dependent on hematocrit. (Pediatr Res 49: 770-776, 2001)
CPB, cardiopulmonary bypass
$\mathrm{CytO}_{2}$, oxidized cytochrome a,a3
DPF, differential path-length factor
$\mathbf{H b O}_{2}$, oxygenated $\mathrm{Hb}$
HbT, total $\mathrm{Hb}$
HHb, deoxygenated $\mathrm{Hb}$
NIRS, near-infrared spectroscopy
TOI, tissue oxygenation index
CCD, charge-coupled device

The surgical outcome for congenital cardiac anomalies has improved in recent years (1). However, children undergoing surgical repair of congenital cardiac anomalies are at significant risk of brain injury $(2,3)$. Availability of a cerebral monitoring system for use during cardiac surgery, especially during $\mathrm{CPB}$, could be useful in preventing postoperative cerebral impairment. NIRS has been used as a noninvasive tool for the assessment of cerebral oxygenation, especially in the fields of anesthesiology, neurology, and neonatology (4-6). Recently, NIRS has also been used in cardiac surgery, and its utility has been reported in both laboratory (7) and clinical applications $(8,9)$. NIRS assessment of cytochrome oxygen-

Received June 29, 2000; accepted January 15, 2001.

Correspondence and reprint requests: Richard A. Jonas, M.D., Department of Cardiac Surgery, Children's Hospital, 300 Longwood Avenue, Boston, MA 02115, U.S.A.; e-mail: richard.jonas@tch.harvard.edu

Supported by National Institutes of Health grant 5R01HL600922 (R.A.J). ation could be a valuable technique to monitor cerebral intraneuronal oxygen delivery during CPB. This information is particularly important because of potentially limited oxygen unloading secondary to hypothermia and alkalosis during $\mathrm{CPB}$, which may make $\mathrm{Hb}$ oxygenation uninformative. The interpretation of NIRS data, however, especially $\mathrm{CytO}_{2}$ signal, remains controversial $(8,10,11)$. The specific absorption spectra of $\mathrm{HbO}_{2}, \mathrm{HHb}$, and cytochrome oxidase overlap and are relatively featureless in the wavelength range that can penetrate several centimeters of tissue, and furthermore, the component of the tissue absorption coefficient caused by $\mathrm{Hb}$ is an order of magnitude greater than that from $\mathrm{CytO}_{2}$ (12). For these reasons, the cytochrome signal is vulnerable to cross-talk with $\mathrm{Hb}$, i.e. changes in the concentration or saturation of $\mathrm{Hb}$ in the head that cause artifactual changes in the cytochrome signal. Moreover, because NIRS is based on the modified Beer-Lambert law, a change of hematocrit might also affect the path length of 
near-infrared light. Kurth and Uher (13) have reported a linear relationship between the intracerebral $\mathrm{Hb}$ level and path length using a time-resolved spectrophotometer. The situation is further complicated for children with congenital heart disease because the $\mathrm{CytO}_{2}$ signal measured by current equipment detects only relative changes from baseline measurement. Children undergoing CPB have different levels of cerebral oxygenation at baseline before $\mathrm{CPB}$ because some are cyanotic whereas others are not cyanotic. It might be difficult to compare the relative $\mathrm{CytO}_{2}$ signal of patients with very different hematocrits and oxygenation before cardiac repair (10). Furthermore, in cardiac surgery large changes of hematocrit occur at the initiation of CPB.

The purpose of the current study is to examine possible cross-talk between the cytochrome and Hb NIRS signals and to clarify the utility and limitations of NIRS during CPB.

\section{METHODS}

\section{Experimental Preparation}

Fifteen 5- to 6-wk-old Yorkshire piglets, weighing $8.79 \pm$ 0.67 kg (Parson's Livestock, Hadley, MA, U.S.A.), were anesthetized with ketamine $(20 \mathrm{mg} / \mathrm{kg})$ and xylazine $(4 \mathrm{mg} / \mathrm{kg})$ intramuscularly and intubated with a 5-mm cuffed endotracheal tube. Each animal was ventilated at a peak inspiratory pressure of $20 \mathrm{~cm} \mathrm{H}_{2} \mathrm{O}$, an inspired oxygen fraction of 0.21 , and a rate of $12-15 \mathrm{breath} / \mathrm{min}$, by means of a pressure control ventilator (Healthdyne model 105; Healthdyne Technologies, Marietta, GA, U.S.A.) to achieve a normal $\mathrm{pH}$ and arterial carbon dioxide tension. For the intraoperative monitoring and blood sampling, arterial and venous lines were placed in the left femoral artery and vein, respectively. After an i.v. bolus injection of fentanyl $(25 \mu \mathrm{g} / \mathrm{kg})$ and pancuronium $(0.5 \mathrm{mg} / \mathrm{kg})$, anesthesia was maintained by a continuous infusion of fentanyl $\left(25 \mu \mathrm{g} \cdot \mathrm{kg}^{-1} \cdot \mathrm{h}^{-1}\right)$ and midazolam $\left(0.2 \mathrm{mg} \cdot \mathrm{kg}^{-1} \cdot \mathrm{h}^{-1}\right)$ along with pancuronium $\left(0.2 \mathrm{mg} \cdot \mathrm{kg}^{-1} \cdot \mathrm{h}^{-1}\right)$ throughout the entire experiment. The right femoral artery was exposed for the CPB arterial cannula, and a median sternotomy was performed to expose the right atrium for venous cannulation. A venous line was placed in the jugular vein via the superior vena cava to measure the jugular venous saturation during the study. After systemic heparinization $(300 \mathrm{IU} / \mathrm{kg})$, an $8 \mathrm{~F}$ arterial cannula (Medtronic Bio-Medicus, Minneapolis, MN, U.S.A.) and a 28F venous cannula (Research Medical, Inc., Midvale, UT, U.S.A.) were inserted into the right femoral artery and right atrial appendage, respectively.

All animals received humane care in compliance with the Principles of Laboratory Animal Care formulated by the National Society for Medical Research and the Guide for the Care and Use of Laboratory Animals prepared by the Institute of Laboratory Animal Resources and published by the National Institutes of Health (NIH publication 86-23, revised 1985).

\section{CPB Technique}

The CPB circuit consisted of a roller-pump, membrane oxygenator (Minimax; Medtronic, Inc., Anaheim, CA, U.S.A.), and sterile tubing, with a $40-\mu \mathrm{m}$ arterial filter (Olson Medical
Sales, Inc., Ashland, MA, U.S.A.). The pump circuit was primed with $800 \mathrm{~mL}$ of whole blood that was taken from a donor piglet on the same day. Methylprednisolone $(30 \mathrm{mg} / \mathrm{kg})$, furosemide $(0.25 \mathrm{mg} / \mathrm{kg})$, and $8.4 \%$ sodium bicarbonate $(10$ $\mathrm{mL}$ ) were added to the priming solution, as is the clinical practice at our hospital. Full bypass flow was set at 100 $\mathrm{mL} \cdot \mathrm{kg}^{-1} \cdot \mathrm{min}^{-1}$. CPB was started, and animals were perfused for $10 \mathrm{~min}$ at normothermia $\left(37^{\circ} \mathrm{C}\right)$. Ventilation was stopped after the establishment of $\mathrm{CPB}$. Esophageal temperature was maintained at $37^{\circ} \mathrm{C}$.

\section{Experimental Protocols}

Experiment 1. After stabilization for $10 \mathrm{~min}$, animals in study group (group $\mathrm{CN}, n=10$ ) received i.v. sodium cyanide $(100 \mathrm{mg} / \mathrm{kg})$ to uncouple cytochrome from $\mathrm{Hb}$ at an initial hematocrit of $35 \%$ (Fig. 1). The hematocrit was then stepwise decreased by $5 \%$ from $35 \%$ to a final hematocrit of $5 \%$ using crystalloid isovolemic hemodilution (Plasmalyte A, Baxter, Deerfield, IL, U.S.A.). NIRS data were recorded using an NIRO 300 device (Hamamatsu Photonics K.K., (Hamamatsu City, Japan), and the jugular venous saturation was measured. In control group (group C, $n=5$ ), a venting cannula was inserted into the left ventricle, and the ascending aorta was clamped to prevent any residual forward blood flow from the heart. Hemodilution was undertaken without sodium cyanide. Pump flow was changed from 100 to 75,50 , and 25 $\mathrm{mL} \cdot \mathrm{kg}^{-1} \cdot \mathrm{min}^{-1}$ at each hematocrit value to alter cerebral blood flow and investigate the influence on NIRS data.

Experiment 2. The NIRO 300 device uses only four wavelengths, $775,810,850$, and $910 \mathrm{~nm}$, to measure and calculate the signals. This measurement system is simple and convenient to use clinically. In contrast, the CCD system (14) uses continuous multiple wavelengths. Thus, the results with the CCD system may be more accurate, although this instrument is less practical. The NIRO 300 device is based on the CCD system. The CCD system can also measure the path length that is dependent on wavelength simultaneously. For these reasons, one additional experiment was performed with the CCD system in place of the NIRO 300 in the same manner as group $\mathrm{CN}$.

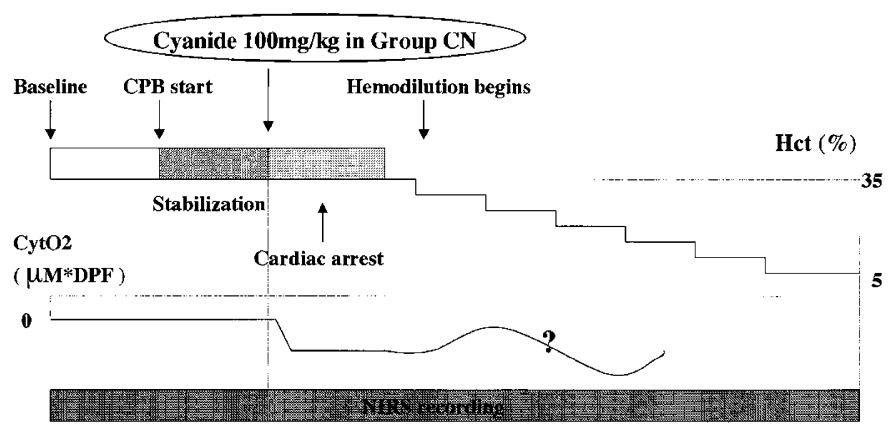

Figure 1. Experimental protocol. CPB was established with right femoral artery and right atrial cannulations at $37^{\circ} \mathrm{C}$. Full bypass flow was set at 100 $\mathrm{mL} \cdot \mathrm{kg}^{-1} \cdot \mathrm{min}^{-1} \mathrm{n}$. Hematocrit was decreased $5 \%$ in steps from 35 to $5 \%$ with crystalloid hemodilution. At each hematocrit value in control piglets, pump flow was changed from 100 to 75,50 , and $25 \mathrm{~mL} \cdot \mathrm{kg}^{-1} \cdot \mathrm{min}^{-1}$. The question mark indicates that the interpretation of the cytochrome signal is controversial. 


\section{Data Collection}

NIRS. A pair of fiberoptic optodes was attached to the head of the animal with a probe holder after induction of anesthesia. The optode spacing was $4.0 \mathrm{~cm}$ in a coronal plane. These two optodes, one a transmitter and one a receiver of laser light of near-infrared wavelength, were connected to the NIRO 300 device. This device calculates the relative concentration changes in $\mathrm{HbO}_{2}, \mathrm{HHb}$, and $\mathrm{CytO}_{2}$, and also calculates TOI. TOI is an index of average tissue $\mathrm{Hb}$ saturation and is calculated independently from the change in $\mathrm{HbO}_{2}$ and $\mathrm{HHb}$. Whereas $\mathrm{HbO}_{2}, \mathrm{HHb}$, and $\mathrm{CytO}_{2}$ are shown as the changes in concentrations from an arbitrary point, TOI is an absolute measure of tissue oxygen saturation independent of $\mathrm{Hb}$. Data collection was begun immediately after intubation, and baseline values were $0 \mu \mathrm{M} \times \mathrm{DPF}$ for $\mathrm{HbO}_{2}, \mathrm{HHb}, \mathrm{HbT}$, and $\mathrm{CytO}_{2}$ signals. Data were recorded every $5 \mathrm{~s}$ throughout the experiment. Measurement was expressed as micromoles per liter times DPF.

Blood gas analyses. Arterial and venous (jugular vein) blood gas values, including electrolyte, glucose, and lactate concentrations, were measured at baseline, 10 min after beginning of CPB (before injection of sodium cyanide), 10 min after injection of cyanide, and $5 \mathrm{~min}$ after the completion of each hemodilution (NOVA 900; Nova Biomedical, Waltham, MA, U.S.A.).

\section{Statistical Analysis}

All results were expressed as mean $\pm \mathrm{SD}$ of the mean. In control piglets in experiment 1 , the average values of hematocrit and NIRS data at each hemodilution point were plotted, and their relationships were determined by comparing linear and nonlinear regression models at each CPB flow. The optimal model, according to correlation coefficients, to describe the relation between hematocrit and $\mathrm{CytO}_{2}$ was a nonlinear logarithmic equation. Relationships between TOI, CPB flow, and jugular vein oxygen saturation were analyzed in the same manner, and a simple linear regression model fits well. A two-tailed $p<0.05$ was considered statistically significant. In study piglets in experiment 1, the relationships between hematocrit and NIRS data were determined by a mixed model ANOVA to account for the repeated measurements within the same piglets. A significant $F$ test was used to indicate a relationship between changes of hematocrit and changes of NIRS data. A two-tailed $p<0.05$ was considered statistically significant. In experiment 2 , the Pearson correlation coefficient was used to evaluate the strength of association between $\mathrm{CytO}_{2}, \mathrm{HbT}$, and path-length data. All data were analyzed by a statistical analysis software package (SPSS version 10.0, SPSS Inc., Chicago, IL, U.S.A.).

\section{RESULTS}

\section{Experiment 1}

Control piglets. Change of hematocrit and hemodynamic state. The hematocrit of animals before CPB was $30.0 \pm 3.0 \%$. It increased to $33.6 \pm 3.6 \%$ after establishment of CPB. Hematocrit was then decreased $5 \%$ in steps to $7.2 \pm 0.8 \%$ by crystalloid hemodilution. Animals showed mean arterial pressure of $79.4 \pm 10.1 \mathrm{~mm} \mathrm{Hg}$ before CPB and $91.4 \pm 9.1 \mathrm{~mm}$ $\mathrm{Hg}$ at a pump flow of $100 \mathrm{~mL} \cdot \mathrm{kg}^{-1} \cdot \mathrm{min}^{-1}$ after the beginning of CPB. There was a decrease of mean arterial pressure during hemodilution such that perfusion pressure was $28.8 \pm 2.6 \mathrm{~mm}$ $\mathrm{Hg}$ at hematocrit of $7.2 \pm 0.8 \%$.

Change of $\mathrm{HbO}_{2}$ and $\mathrm{CytO}_{2} . \mathrm{HbO}_{2}$ increased from 0 to 43.1 $\pm 35.9 \mu \mathrm{M} \times \mathrm{DPF}$, and $\mathrm{CytO}_{2}$ increased to $3.4 \pm 3.3$ $\mu \mathrm{M} \times \mathrm{DPF}$ after the beginning of CPB (Table 1, Fig. 2). Hemodilution subsequently resulted in a linear decrease in $\mathrm{HbO}_{2}\left(R^{2}=0.993, p<0.0001\right)$ and a logarithmic decrease of $\mathrm{CytO}_{2}\left(R^{2}=0.951, p<0.0001\right)$ at a pump flow of 100 $\mathrm{mL} \cdot \mathrm{kg}^{-1} \cdot \mathrm{min}^{-1}$. The logarithmic correlation was affected by the pump flow.

Change of $\mathrm{HHb}$. HHb changed little at the initiation of CPB. There was significant correlation between hematocrit and $\mathrm{HHb}$ during hemodilution $\left(R^{2}=0.923, p<0.0001\right)$.

Change of TOI. Animals showed a mean TOI of $48.4 \pm$ $3.2 \%$ before CPB. TOI increased to $56.8 \pm 4.1 \%$ after the establishment of CPB. TOI was not much influenced by hematocrit, but showed a positive correlation with pump flow $\left(R^{2}\right.$ $=0.976, p=0.013$ ).

Study piglets. Change of hematocrit and hemodynamic state. The hematocrit of animals before CPB was $28.4 \pm 2.3 \%$ and increased to $34.7 \pm 2.7 \%$ after establishment of CPB. The injection of sodium cyanide caused some change of hematocrit to $32.5 \pm 2.7 \%$ because $50 \mathrm{~mL}$ of saline was used to dissolve the sodium cyanide. Hemodilution decreased the hematocrit stepwise by $5 \%$ to $6.7 \pm 0.8 \%$. Animals showed mean arterial pressure of $72.8 \pm 6.4 \mathrm{~mm} \mathrm{Hg}$ before CPB and $80.4 \pm 15.2$ $\mathrm{mm} \mathrm{Hg}$ after the beginning of CPB. Sodium cyanide resulted in a decrease to $31.6 \pm 4.6 \mathrm{~mm} \mathrm{Hg}$. There was a mild decrease of mean arterial pressure during hemodilution to $24.5 \pm 17.0 \mathrm{~mm}$ $\mathrm{Hg}$ at the end of the experiment.

Table 1. Change of NIRS signals before hemodilution in both groups

\begin{tabular}{|c|c|c|c|c|c|}
\hline Group & $\begin{array}{c}\mathrm{HbO}_{2} \\
(\mu \mathrm{M} \times \mathrm{DPF})\end{array}$ & $\begin{array}{c}\mathrm{HHb} \\
(\mu \mathrm{M} \times \mathrm{DPF})\end{array}$ & $\begin{array}{c}\mathrm{HbT} \\
(\mu \mathrm{M} \times \mathrm{DPF})\end{array}$ & $\begin{array}{c}\mathrm{CytO}_{2} \\
(\mu \mathrm{M} \times \mathrm{DPF})\end{array}$ & TOI $(\%)^{*}$ \\
\hline \multicolumn{6}{|l|}{ Group CN } \\
\hline Before CPB & 0 & 0 & 0 & 0 & $46.4 \pm 1.7$ \\
\hline During CPB before cyanide & $62.9 \pm 25.6$ & $-4.6 \pm 7.8$ & $58.4 \pm 27.0$ & $1.9 \pm 1.8$ & $55.4 \pm 4.0$ \\
\hline After cyanide & $132.3 \pm 48.9$ & $-70.8 \pm 22.1$ & $61.5 \pm 41.0$ & $-7.0 \pm 2.6$ & $73.7 \pm 3.9$ \\
\hline \multicolumn{6}{|l|}{ Group C } \\
\hline Before CPB & 0 & 0 & 0 & 0 & $48.4 \pm 3.2$ \\
\hline During CPB & $43.1 \pm 35.9$ & $-0.8 \pm 27.4$ & $42.3 \pm 44.0$ & $3.4 \pm 3.3$ & $56.8 \pm 4.1$ \\
\hline
\end{tabular}

\footnotetext{
* TOI is the ratio of tissue oxygenated and total hemoglobin, as follows: $\mathrm{TOI}=\left(\mathrm{HbO}_{2} \mathrm{vol} / \mathrm{HbT} \mathrm{vol}\right) \times 100 \%$.
} 
A
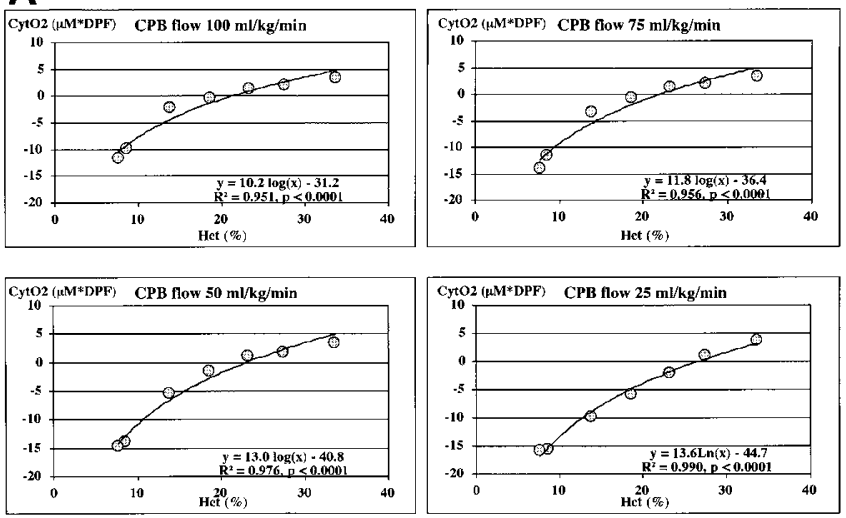

B
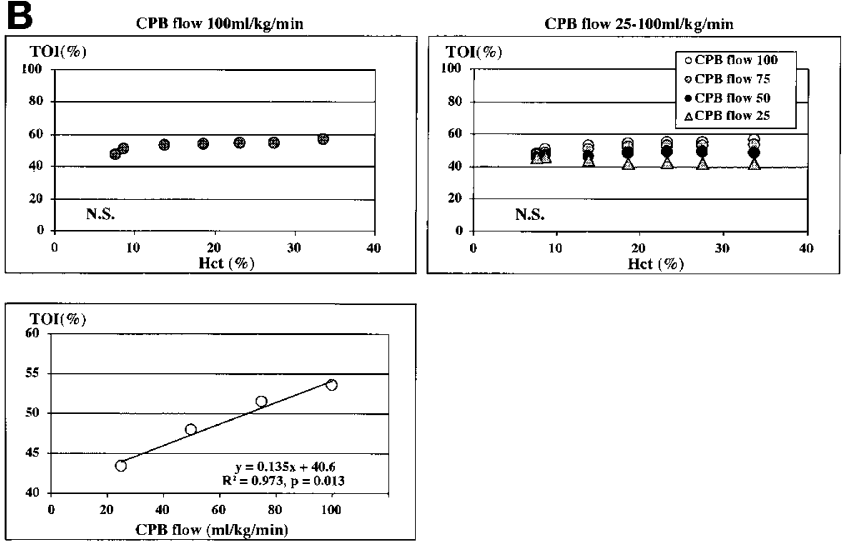

Figure 2. Change of $\mathrm{CytO}_{2}(A)$ and TOI $(B)$ during hemodilution in group C. $\mathrm{CytO}_{2}$ signal decreased logarithmically during hemodilution $\left(R^{2}=0.951, p<\right.$ 0.0001 ) and was affected by the pump flow. TOI was not much influenced by hematocrit value, but showed a positive correlation with pump flow $\left(R^{2}=\right.$ $0.973, p=0.013)$.

Blood gas analyses. The results are shown in Table 2. The administration of sodium cyanide caused large increases in potassium, lactate, and jugular venous saturation.

Change of $\mathrm{HbO}_{2}$ and $\mathrm{CytO}_{2} . \mathrm{HbO}_{2}$ increased $62.9 \pm 25.6$ $\mu \mathrm{M} \times \mathrm{DPF}$ units, and $\mathrm{CytO}_{2}$ increased $1.9 \pm 1.8 \mu \mathrm{M} \times \mathrm{DPF}$ units after the beginning of CPB (Table 1, Fig. 3). Sodium cyanide caused $\mathrm{HbO}_{2}$ to increase $132.3 \pm 48.9 \mu \mathrm{M} \times \mathrm{DPF}$, and $\mathrm{CytO}_{2}$ decreased by $7.0 \pm 2.6 \mu \mathrm{M} \times \mathrm{DPF}$ units as anticipated, confirming uncoupling of electron transport. Hemodilution

Table 2. Blood gas data before hemodilution in group $C N$

\begin{tabular}{lccc}
\hline & & \multicolumn{2}{c}{ During CPB } \\
\cline { 3 - 4 } & Before CPB & Before cyanide & After cyanide \\
\hline $\mathrm{pH}$ & $7.518 \pm 0.042$ & $7.473 \pm 0.042$ & $7.343 \pm 0.090$ \\
$\mathrm{PaCO}_{2}(\mathrm{~mm} \mathrm{Hg})$ & $35.11 \pm 3.96$ & $44.48 \pm 5.82$ & $61.88 \pm 7.33$ \\
$\mathrm{PaO}_{2}(\mathrm{~mm} \mathrm{Hg})$ & $104.43 \pm 7.45$ & $414.04 \pm 66.83$ & $559.50 \pm 36.86$ \\
$\mathrm{Hct}(\%)$ & $28.4 \pm 2.3$ & $34.2 \pm 2.7$ & $32.5 \pm 2.7$ \\
$\mathrm{~K}(\mathrm{mM})$ & $3.74 \pm 0.35$ & $4.30 \pm 0.94$ & $8.32 \pm 1.17$ \\
$\mathrm{Glucose}(\mathrm{mg} / \mathrm{dL})$ & $110.5 \pm 17.8$ & $133.1 \pm 34.2$ & $75.7 \pm 25.8$ \\
Lactate $(\mathrm{mM})$ & $1.47 \pm 0.59$ & $2.64 \pm 1.10$ & $20.00 \pm 2.69$ \\
$\mathrm{SjO}_{2}(\%)$ & $79.96 \pm 7.68$ & $84.82 \pm 8.16$ & $99.85 \pm 0.16$ \\
\hline
\end{tabular}

Administration of sodium cyanide caused large increases in potassium and lactate, and elevated jugular venous saturation.

$\mathrm{PaCO}_{2}$, arterial $\mathrm{PCO}_{2} ; \mathrm{PaO}_{2}$, arterial $\mathrm{PO}_{2} ; \mathrm{Hct}$, hematocrit; $\mathrm{Sjo}_{2}$, jugular venous oxygen saturation.
A
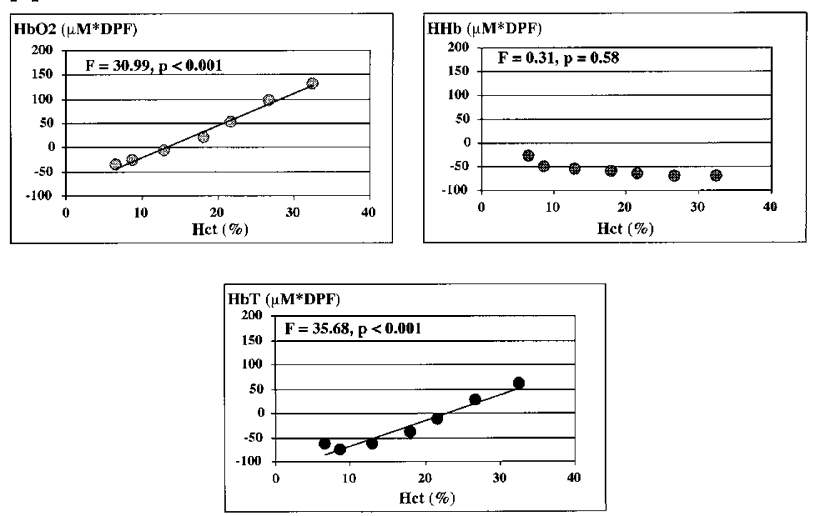

B
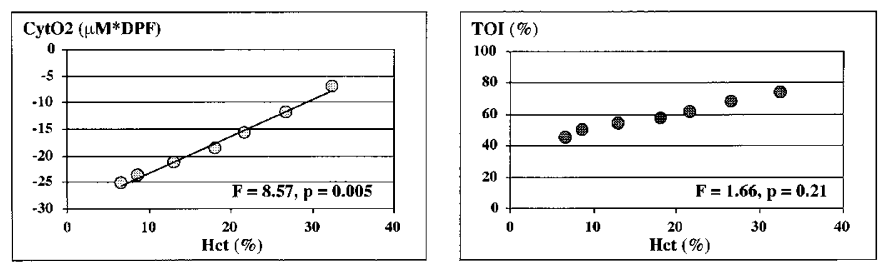

Figure 3. $A, B$, Change of NIRS signals during hemodilution in group $\mathrm{CN}$. Hemodilution resulted in linear decreases in $\mathrm{CytO}_{2}(F=30.99, p<0.001)$, suggesting important cross-talk between the $\mathrm{Hb}$ and cytochrome signals inasmuch as cytochrome is only intracellular.

subsequently resulted in linear decreases of $\mathrm{HbO}_{2}(F=30.99$, $p<0.001)$ and $\mathrm{CytO}_{2}(F=8.57, p<0.001)$.

Change of $\mathrm{HHb}$. $\mathrm{HHb}$ did not change importantly at the initiation of CPB. After the bolus injection of sodium cyanide, $\mathrm{HHb}$ decreased $-70.8 \pm 22.1 \mu \mathrm{M} \times \mathrm{DPF}$. There was no significant relationship between hematocrit and $\mathrm{HHb}$ during hemodilution $(F=0.31, p=0.58)$.

Relationship between $\mathrm{HbT}$ and $\mathrm{CytO}_{2}$. Changes in $\mathrm{CytO}_{2}$ were highly correlated with changes in $\mathrm{HbT}$ during hemodilution. If blood flow to the brain is constant during hemodilution, changes in $\mathrm{HbT}$ indicate the intracerebral $\mathrm{Hb}$ concentration.

Change of TOI. Animals showed a mean TOI of $46.4 \pm$ $1.7 \%$ before CPB. TOI increased to $55.4 \pm 4.0 \%$ after the establishment of CPB and showed further increase to $73.7 \pm$ $3.9 \%$ after the injection of sodium cyanide. There was no significant relationship between hematocrit and TOI during hemodilution $(F=1.66, p=0.21)$.

\section{Experiment 2}

The data derived with the CCD device are shown in Figure 4. During hemodilution after the injection of cyanide, $\mathrm{CytO}_{2}$ signal decreased according to hematocrit value. Wavelengthdependent path length that was measured throughout the experiment changed according to $\mathrm{HbT}$ level, which represents the change of hematocrit. There was a linear relationship between $\mathrm{HbT}, \mathrm{CytO}_{2}$, and path length after the injection of sodium cyanide.

\section{DISCUSSION}

Cerebral hypoxia and ischemia are the most common cause of neurologic and neuropsychological deficits in infants and 

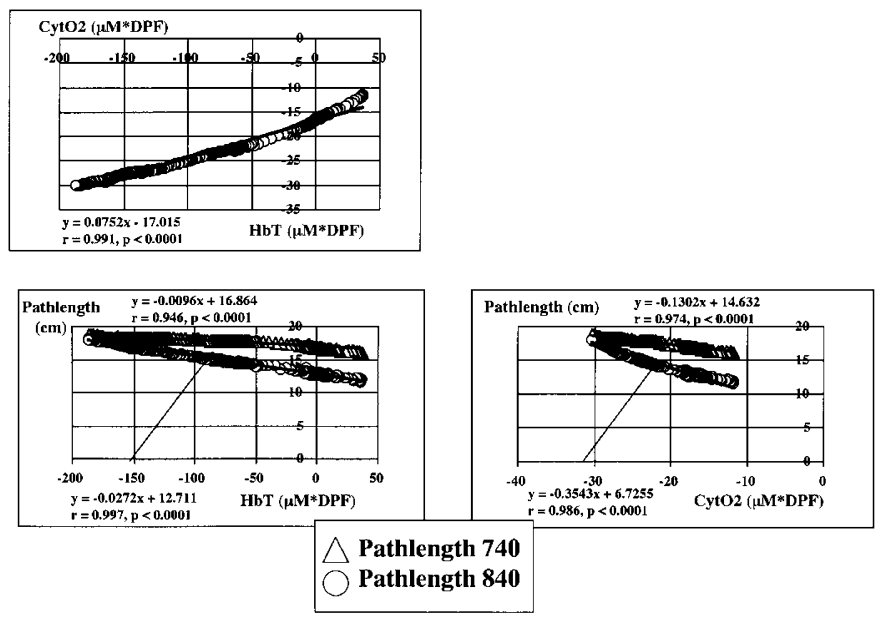

Figure 4. Top left, relationship between $\mathrm{HbT}$ and $\mathrm{CytO}_{2}$ during hemodilution after cyanide. Data were recorded by CCD system. Bottom, change of path length during hemodilution after cyanide. The term "Path length 740 (840)" means the path length that is dependent on wavelength of $740(840) \mathrm{nm}$

children after cardiac repair $(2,3)$. A method is needed to monitor cerebral oxygenation and guide operative management to prevent severe hypoxia and ischemia during CPB. Presently available methods of monitoring, e.g. EEG, measurement of cerebral blood flow, and jugular venous saturation, are unreliable or irrelevant under conditions of deep hypothermia, hemodilution, $\mathrm{pH}$ shifts, and circulatory arrest. NIRS would seem to be ideal for the cardiac surgeon because it can monitor cerebral oxygenation continuously during surgery. The cytochrome signal in particular would be a useful indicator of intracellular hypoxia and impending injury. However, the cytochrome signal represents a small component of the total attenuation change and therefore is vulnerable to artifact. Accordingly, the interpretation of NIRS data, especially the $\mathrm{CytO}_{2}$ value, still remains controversial $(8,10,11)$.

Several factors, such as hematocrit, $\mathrm{pH}$, temperature, or pump flow, are manipulated over wide ranges during CPB for congenital heart disease. Kurth and Uher (13) have reported previously that hematocrit interferes with the cytochrome signal. Our study confirms such interference in the setting of an animal model with CPB. The results of the current study demonstrate that the $\mathrm{CytO}_{2}$ signal measured by the NIRO 300 device in 5- to 6-wk-old piglets is highly dependent on the hematocrit value.

There have been several previous studies of cross-talk between $\mathrm{Hb}$ and cytochrome. Investigators have used cyanide, which is a mitochondrial inhibitor $(15,16)$. However, it is not feasible to perform such studies completely without CPB. Because cyanide stops the mitochondrial function of the heart simultaneously with the brain, it is impossible to maintain blood flow to the brain after the injection of cyanide without $\mathrm{CPB}$. In previous reports, the heart of the experimental animal was beating throughout the study, keeping the mean blood pressure $>40 \mathrm{~mm} \mathrm{Hg}$ (16). The dose of cyanide ( $5 \mathrm{mg} / \mathrm{kg}$ body weight) is insufficient to completely inhibit mitochondrial function. To ensure complete mitochondrial inhibition with cyanide has been achieved, the experiment has to be performed under $\mathrm{CPB}$ as in the current study.
After administration of a saturating quantity of sodium cyanide, mitochondrial oxygen consumption should be completely inhibited and the cytochrome oxidase redox state should be locked in the fully reduced state and independent of intracellular oxygen tension. The $\mathrm{CytO}_{2}$ signal should fall to a nadir level and be independent of cerebral saturation and $\mathrm{Hb}$ concentration. In this study, $\mathrm{Hb}$ concentration was changed by varying the pump circuit hematocrit, and it was found that the cytochrome signal continued to change with each step of hemodilution after the administration of cyanide. There are two possible explanations for this phenomenon. First, the dose of sodium cyanide may have been insufficient to completely inhibit mitochondrial respiration, that is, cytochrome oxidase was not fully reduced after administration of cyanide and further reduction occurred during hemodilution because of the decrease in oxygen delivery. Second, the NIR system was unable to precisely separate the $\mathrm{Hb}$ and cytochrome oxidase components of the change in attenuation, leading to artifactual changes in the cytochrome signal.

In the current study, sodium cyanide was administered i.v. at a dose of $100 \mathrm{mg} / \mathrm{kg}$, which is 20 times the dose believed to have fully reduced the cerebral cytochrome signal in a previous study on newborn piglets (16). It is generally agreed that the lethal dose is approximately $5-10 \mathrm{mg} / \mathrm{kg}(17,18)$. In our study the lactate concentration increased from $2.64 \pm 1.10$ to 20.00 $\pm 2.69 \mathrm{mM}$, and jugular venous saturation increased from $84.82 \pm 8.16 \%$ to $99.85 \pm 0.16 \%$. These changes confirm the efficacy of sodium cyanide in inhibiting oxygen consumption and are strong evidence that cerebral cytochrome oxidase was fully reduced after administration of cyanide. In addition, the inhibitory dissociation constant of cytochrome oxidase for cyanide is $0.2 \mu \mathrm{M}$, which is four orders of magnitude smaller than the average concentration of cyanide in the piglet body $(100 \mathrm{mg} / \mathrm{kg}$ is approximately $2 \mathrm{mM})(19)$. We can therefore say with some certainty that the cyanide is at a saturating concentration. Further evidence supporting complete inhibition of oxygen consumption is that jugular venous saturation rose to near $100 \%$. In light of this, it must be concluded that the additional cytochrome oxidase reductions after cyanide administration were artifactual in origin. The assumptions behind the modified Beer-Lambert law are that the optodes do not move with respect to the tissue, the tissue scattering coefficient does not change, and the change in absorption coefficient is small.

This study also examined path length $(20-22)$. The factors that can change path length are optode placement, geometry of the skull, tissue edema, and absorption and scattering of light. The optodes, transmitter and receiver, are separated by a distance of $4.0 \mathrm{~cm}$ throughout the experiment, and therefore optode placement does not affect the path length. Regarding geometry of the skull, the piglets used in the current study have skull and extracranial tissue (skin and fat) approximately $4 \mathrm{~mm}$ thick. Because the near-infrared light can penetrate to a depth of $\geq 2 \mathrm{~cm}$ with the optode distance of $4 \mathrm{~cm}$, the data should reflect changes in brain tissue $(23,24)$. However, tissue edema occurs during CPB (25), particularly after the injection of cyanide, and very large changes in $\mathrm{CytO}_{2}$ signal were found during hemodilution. $\mathrm{CytO}_{2}$ signal decreased from $-7.0 \pm 2.6$ $\mu \mathrm{M} \times \mathrm{DPF}$ at a hematocrit of $32.5 \pm 2.7 \%$ to $-24.3 \pm 2.2$ 
$\mu \mathrm{M} \times \mathrm{DPF}$ at the final hematocrit of $6.7 \pm 0.8 \%$. It seems difficult to explain such large changes, which are three times more than the change with administration of cyanide, by tissue edema alone. Full spectral NIRS such as we used in experiment 2 with the CCD system has the added advantage that the differential path length can be measured from the water features using the second differential technique. Furthermore, modeling has shown that full spectral systems can better separate the cytochrome signal from the $\mathrm{Hb}$ signals compared with four wavelength systems such as the NIRO 300 (26). Change of path length was indeed found according to the degree of hemodilution in this additional experiment. (There was no change of path length dependent on wavelength of 840 $\mathrm{nm}$ before and after the injection of cyanide, although there was approximately a 50\% increase of path length dependent on wavelength of $740 \mathrm{~nm}$. Afterward, there were approximately 50 and $20 \%$ increases in path length during hemodilution, respectively). Hemodilution increased path length, and for this reason also an anomalous $\mathrm{CytO}_{2}$ signal can be produced. However, inasmuch as all the units are multiplied by DPF, path length affects all the changes in the $\mathrm{CytO}_{2}$ signal.

In group $\mathrm{C}, \mathrm{CytO}_{2}$ signal decreased logarithmically during hemodilution and was affected by the pump flow. $\mathrm{CytO}_{2}$ signal decreased $0.6858 \mu \mathrm{M} \times \mathrm{DPF}$ in steps with a hematocrit decrease of $1 \%$ in group $\mathrm{CN}$. In group $\mathrm{C}$, the negative slope of $\mathrm{CytO}_{2}$ signal was dependent on hematocrit value at each point $\left(10.2371 /\right.$ hematocrit when CPB flow is $\left.100 \mathrm{~mL} \cdot \mathrm{kg}^{-1} \cdot \mathrm{min}^{-1}\right)$, and this negative slope became steeper with further decrease of hematocrit. When we apply the relation in group $\mathrm{CN}$ to the result in group $\mathrm{C}$, a hematocrit of $14.9 \%(10.2371 / 0.6858)$ is necessary to maintain cerebral oxygenation with CPB flow of $100 \mathrm{~mL} \cdot \mathrm{kg}^{-1} \cdot \mathrm{min}^{-1}$. Interestingly, this hematocrit is almost the same as the minimum safe hematocrit described previously $(27,28)$, although our own studies suggest that this is not an optimal hematocrit $(29,30)$. If an algorithm can be developed to correct for hematocrit changes, the $\mathrm{CytO}_{2}$ signal measured by NIRS would more accurately assess cytochrome and could provide important information during CPB (31).

The NIRO 300 calculates $\mathrm{HbO}_{2}, \mathrm{HHb}, \mathrm{HbT}$, and $\mathrm{CytO}_{2}$ from the modified Beer-Lambert law and TOI with spatially resolved spectroscopy (32). TOI was not influenced by hematocrit value and showed a positive correlation with pump flow. However, there was no significant relationship between TOI and the jugular venous saturation. Sagittal sinus saturation is lower than the mixed venous saturation (33). This value seems to be close to the TOI value before CPB in the current piglet model. Therefore, TOI as a predictor of cerebral oxygenation may be more reliable than the other variables under conditions of CPB.

In conclusion, TOI may be a useful indicator for brain oxygenation during CPB. The cytochrome signal as presently measured by NIRS is highly dependent on hematocrit. Modeling to correct for this problem is being undertaken, so that an algorithm can be developed to correct the hematocrit changes such as occur under the conditions of CPB.

Acknowledgments. The authors thank Cheryl Carney and Jason Balara for their technical assistance. David Zurakowski,
Ph.D., from the Department of Biostatistics at Children's Hospital, Boston, provided us with valuable advice regarding the statistical analysis. We also thank Hamamatsu Photonics, K.K. for their support.

\section{REFERENCES}

1. Castaneda AR, Jonas RA, Mayer JE, Hanley FL 1994 Cardiac Surgery of the Neonate and Infant. WB Saunders, Philadelphia, pp 141-478

2. Newburger JW, Jonas RA, Wernovsky G, Wypij D, Hickey PR, Kuban KC, Farrell DM, Holmes GL, Helmers SL, Constantinou J, Carrazana E, Barlow JK, Walsh AZ, Lucius KC, Share JC, Wessel DL, Hanley FL, Mayer JE, Castaneda AR, Ware JH 1993 A comparison of the perioperative neurologic effects of hypothermic circulatory arrest versus low-flow cardiopulmonary bypass in infant heart surgery. N Engl J Med 329:1057-1064

3. Bellinger DC, Wypij D, Kuban KC, Rappaport LA, Hickey PR, Wernovsky G, Jonas RA, Newburger JW 1999 Developmental and neurological status of children at 4 years of age after heart surgery with hypothermic circulatory arrest or low-flow cardiopulmonary bypass. Circulation 100:526-532

4. Jobsis FF 1977 Noninvasive, infrared monitoring of cerebral and myocardial oxygen sufficiency and circulatory parameters. Science 198:1264-1267

5. Wahr JA, Tremper KK, Samra S, Delpy DT 1996 Near-infrared spectroscopy: theory and applications. J Cardiothorac Vasc Anesth 10:406-418

6. Wyatt JS, Cope M, Delpy DT, Wray S, Reynolds EO 1986 Quantification of cerebral oxygenation and haemodynamics in sick newborn infants by near infrared spectrophotometry. Lancet 2:1063-1066

7. Nomura F, Naruse H, duPlessis A, Hiramatsu T, Forbess J, Holtzman D, Volpe JJ, Jonas R, Tsuji M 1996 Cerebral oxygenation measured by near infrared spectroscopy during cardiopulmonary bypass and deep hypothermic circulatory arrest in piglets. Pediatr Res 40:790-796

8. Nollert G, Mohnle P, Tassani-Prell P, Uttner I, Borasio GD, Schmoeckel M, Reichart B 1995 Postoperative neuropsychological dysfunction and cerebral oxygenation during cardiac surgery. Thorac Cardiovasc Surg 43:260-264

9. Kunihara T, Myojin K, Matano J, Tamura M 1995 Clinical study on measurement of cerebral metabolism and oxygenation during cardio-pulmonary bypass by nearinfrared spectrophotometry. Nippon Kyobu Geka Gakkai Zasshi 43:1107-1114

10. Skov L, Greisen G 1994 Apparent cerebral cytochrome aa3 reduction during cardiopulmonary bypass in hypoxaemic children with congenital heart disease: a critical analysis of in vivo near-infrared spectrophotometric data. Physiol Meas 15:447-457

11. Matsumoto H, Oda T, Hossain MA, Yoshimura N 1996 Does the redox state of cytochrome aa 3 reflect brain energy level during hypoxia? Simultaneous measurements by near infrared spectrophotometry and ${ }^{31} \mathrm{P}$ nuclear magnetic resonance spectroscopy. Anesth Analg 83:513-518

12. Cope M, Delpy DT 1988 System for long-term measurement of cerebral blood and tissue oxygenation on newborn infants by near infra-red transillumination. Med Biol Eng Comput 26:289-294

13. Kurth CD, Uher B 1997 Cerebral hemoglobin and optical pathlength influence near-infrared spectroscopy measurement of cerebral oxygen saturation. Anesth Analg 84:1297-1305

14. Cope M, Delpy DT, Wray S, Wyatt JS, Reynolds EO 1989 A CCD spectrophotometer to quantitate the concentration of chromophores in living tissue utilising the absorption peak of water at $975 \mathrm{~nm}$. Adv Exp Med Biol 248:33-40

15. Miyake H, Nioka S, Zaman A, Smith DS, Chance B 1991 The detection of cytochrome oxidase heme iron and copper absorption in the blood-perfused and blood-free brain in normoxia and hypoxia. Anal Biochem 192:149-155

16. Cooper CE, Cope M, Springett R, Amess PN, Penrice J, Tyszczuk L, Punwani S, Ordidge R, Wyatt J, Delpy DT 1999 Use of mitochondrial inhibitors to demonstrate that cytochrome oxidase near-infrared spectroscopy can measure mitochondrial dysfunction noninvasively in the brain. J Cereb Blood Flow Metab 19:27-38

17. Pettersen JC, Cohen SD 1993 The effects of cyanide on brain mitochondrial cytochrome oxidase and respiratory activities. J Appl Toxicol 13:9-14

18. Salkowski AA, Penney DG 1995 Metabolic, cardiovascular, and neurologic aspects of acute cyanide poisoning in the rat. Toxicol Lett 75:19-27

19. Petersen LC 1977 The effect of inhibitors on the oxygen kinetics of cytochrome $c$ oxidase. Biochim Biophys Acta 11:299-307

20. Wyatt JS, Cope M, Delpy DT, van der Zee P, Arridge S, Edwards AD, Reynolds EO 1990 Measurement of optical path length for cerebral near-infrared spectroscopy in newborn infants. Dev Neurosci 12:140-144

21. van der Zee P, Cope M, Arridge SR, Essenpreis M, Potter LA, Edwards AD, Wyat JS, McCormick DC, Roth SC, Reynolds EO, Delpy DT 1992 Experimentally measured optical pathlengths for the adult head, calf and forearm and the head of the newborn infant as a function of inter optode spacing. Adv Exp Med Biol 316:143-153

22. Duncan A, Meek JH, Clemence M, Elwell CE, Tyszczuk L, Cope M, Delpy DT 1995 Optical pathlength measurements on adult head, calf and forearm and the head of the newborn infant using phase resolved optical spectroscopy. Phys Med Biol 40:295-304

23. Wyatt JS, Cope M, Delpy DT, Richardson CE, Edwards AD, Wray S, Reynolds EO 1990 Quantitation of cerebral blood volume in human infants by near-infrared spectroscopy. J Appl Physiol 68:1086-1091

24. Edwards AD, Richardson C, van der Zee P, Elwell C, Wyatt JS, Cope M, Delpy DT, Reynolds EO 1993 Measurement of hemoglobin flow and blood flow by near-infrared spectroscopy. J Appl Physiol 75:1884-1889

25. Harris DN, Bailey SM, Smith PL, Taylor KM, Oatridge A, Bydder GM 1993 Brain swelling in first hour after coronary artery bypass surgery. Lancet 342:586-587 
26. Matcher SJ, Cope M, Delpy DT 1994 Use of the water absorption spectrum to quantify tissue chromophore concentration changes in near-infrared spectroscopy. Phys Med Biol 39:177-196

27. Cook DJ, Orszulak TA, Daly RC, MacVeigh I 1997 Minimum hematocrit fo normothermic cardiopulmonary bypass in dogs. Circulation 96(suppl 2):II-200-II204

28. Cook DJ, Orszulak TA, Daly RC 1998 Minimum hematocrit at differing cardiopulmonary bypass temperatures in dogs. Circulation 98(suppl 2):II-170-II-174

29. Shin'oka T, Shum-Tim D, Jonas RA, Lidov HG, Laussen PC, Miura T, du Plessis A 1996 Higher hematocrit improves cerebral outcome after deep hypothermic circulatory arrest. J Thorac Cardiovasc Surg 112:1610-1620
30. Shin'oka T, Shum-Tim D, Laussen PC, Zinkovsky SM, Lidov HG, du Plessis A, Jonas RA 1998 Effects of oncotic pressure and hematocrit on outcome after hypothermic circulatory arrest. Ann Thorac Surg 65:155-164

31. Matcher SJ, Elwell CE, Cooper CE, Cope M, Delpy DT 1995 Performance comparison of several published tissue near-infrared spectroscopy algorithms. Anal Biochem 227:54-68

32. Suzuki S, Takasaki S, Ozaki T, Kobayashi Y 1999 A tissue oxygenation monitor using NIR spatially resolved spectroscopy. Proc SPIE 3597:582-592

33. McDaniel LB, Zwischenberger JB, Vertrees RA, Nutt L, Uchida T, Nguyen T, Kramer GC 1995 Mixed venous oxygen saturation during cardiopulmonary bypass poorly predicts regional venous saturation. Anesth Analg 80:466-472 